\title{
Plant Species Composition Can Be Used as a Proxy to Predict Methane Emissions in Peatland Ecosystems After Land-Use Changes
}

\author{
André T. C. Dias, ${ }^{1,2 *}$ Bart Hoorens, ${ }^{1,3}$ Richard S. P. Van Logtestijn, ${ }^{1}$ \\ Jan E. Vermaat, ${ }^{4}$ and Rien Aerts ${ }^{1}$
}

\begin{abstract}
${ }^{1}$ Department of Systems Ecology, Institute of Ecological Science, VU University Amsterdam, De Boelelaan 1087, 1081 HV Amsterdam, The Netherlands; ${ }^{2}$ Department of Animal Ecology, Institute of Ecological Science, VU University Amsterdam, De Boelelaan 1085, 1081 HV Amsterdam, The Netherlands; ${ }^{3}$ Tauw Consulting, Australiëlaan 5, Postbus 3015, 3502 GA Utrecht, The Netherlands; ${ }^{4}$ Institute for Environmental Studies, VU University Amsterdam, De Boelelaan 1087, 1081 HV Amsterdam, The Netherlands
\end{abstract}

\begin{abstract}
Land-use change in peatlands affects important drivers of $\mathrm{CH}_{4}$ emission such as groundwater level and nutrient availability. Due to the high spatial and temporal variability of such environmental drivers, it is hard to make good predictions of $\mathrm{CH}_{4}$ emissions in the context of land-use changes. Here, we used plant species composition as a stable integrator of environmental drivers of $\mathrm{CH}_{4}$ emissions. We used weighted averaging regression and calibration to make a direct link between plant species composition and $\mathrm{CH}_{4}$ flux in an effort to predict values of $\mathrm{CH}_{4}$ emission for a land-use gradient in two extensive peatland sites. Our predicted $\mathrm{CH}_{4}$ emissions showed good fit with observed values. Additionally, we showed that a quick characterization of vegetation composition, by the dominant species only, provides equally good predictions of $\mathrm{CH}_{4}$ emissions. The use of
\end{abstract}

mean groundwater level alone for predicting emissions showed the same predictive power as our models. However, water level showed strong variability in time. Furthermore, the inverse relationship between water level and $\mathrm{CH}_{4}$ emission can lead to higher errors in predictions at sites with higher $\mathrm{CH}_{4}$ emission. The performance of our model was comparable with those of mechanistic models developed for natural wetland ecosystems. However, such mechanistic models require complex input parameters that are rarely available. We propose the use of plant species composition as a simple and effective alternative for deriving predictions of $\mathrm{CH}_{4}$ emissions in peatlands in the context of land-use change.

Key words: fens; greenhouse gases; groundwater level; modeling; transfer functions; wetlands.
Received 4 November 2009; accepted 16 April 2010; published online 11 May 2010

Electronic supplementary material: The online version of this article (doi:10.1007/s10021-010-9338-1) contains supplementary material, which is available to authorized users.

Author Contributions: André T. C. Dias performed research, analyzed data, and wrote the article. Bart Hoorens designed the survey and performed research. Richard S. P. van Logtestijn performed research. Jan E. Vermaat designed the survey, performed research, and contributed to manuscript writing. Rien Aerts designed the survey and contributed to manuscript writing.

*Corresponding author; e-mail: andre.dias@falw.vu.nl

\section{INTRODUCTION}

Although peatland ecosystems cover a small proportion of the global terrestrial surface, they store up to one-third of the soil carbon (C) pool (Gorham 1991). Despite their role as global C sinks, peatlands are an important source of methane to the atmosphere, which has a global warming potential 23 times higher than carbon dioxide in a 100-year 
horizon (Whalen 2005). In Europe, land-use change from natural peatland ecosystems to drained agricultural lands has led to considerable change in the $\mathrm{C}$ balance, converting these areas into significant sources of carbon dioxide to the atmosphere due to high rates of peat soil oxidation (Langeveld and others 1997). On the other hand, such land-use change significantly reduced methane emissions due to the reduction of the anaerobic conditions necessary to methane production (Hendriks and others 2007; Langeveld and others 1997). Because of the high $C$ storage and their vulnerability to land-use change, biogeochemical processes in peatlands have received considerable attention (Limpens and others 2008). Particularly the emission of greenhouse gases (GHGs), such as carbon dioxide and methane, has been the focus of many biogeochemical studies in peatlands due to their potential contribution to climate change (Aerts and Toet 1997; Glatzel and others 2008; Hendriks and others 2007; Lapveteläinen and others 2007; Veenendaal and others 2007; Wilson and others 2008).

Especially in western and northern Europe, peatlands have been changed due to human activities, such as reclamation for agriculture and forestry. Such land-use change includes management practices that can strongly affect methane emission, like groundwater level regulation (Aerts and Ludwig 1997; Bubier 1995; Le Mer and Roger 2001) and fertilization (Aerts and Toet 1997; Le Mer and Roger 2001). Groundwater level is often positively related with methane emission, because higher water levels reduce the soil aerobic zone where methane is oxidized by methanotrophic bacteria (Le Mer and Roger 2001; Whalen 2005). Fertilization generally increases methane emission, not only when organic fertilizers are used due to the input of easily degradable organic matter (Le Mer and Roger 2001), but also when inorganic N compounds are added to peat soils (Aerts and De Caluwe 1999). Although there is considerable knowledge of the effects of these drivers on methane emissions, these variables show high variability through time. Water table level can vary greatly between seasons but also shows high variation within the season. For instance, high values can be reported shortly after strong precipitation events. Labile C might also show higher values shortly after manure addition, decreasing during the growing season with microbial consumption and leaching. As such, despite our process-based knowledge, it is hard to make good predictions of methane emissions in the context of land-use change. This is a pressing issue due to the national and international obligations that countries face in meeting their Kyoto obligations (Penman and others 2003).

A way to overcome this problem is to use proxies that may lead to more robust predictions of methane emissions in response to land-use change. A potentially powerful proxy could be plant species composition of peatland ecosystems as a stable integrator, both in space and time, of the abiotic and possibly biotic drivers of methane emission. Other studies already recognized the potential of vegetation as an indirect indicator of methane flux on natural ecosystems because it integrates several environmental variables which can drive both methane emission and plant species composition (Bubier 1995; Bubier and others 1995; Wilson and others 2008). Moreover, the vascular transport of methane to the atmosphere, bypassing the soil aerobic zone, can have important impacts on emissions. It has been reported that $55-85 \%$ of methane emissions from peatlands are plant-mediated (Waddington and others 1996). Therefore, the use of plant species composition as a proxy for methane emission can help to provide better estimates of emissions due to land-use change, because emissions related to land use are controlled by a combination of biological, climatological, and management factors.

A common feature of managed peatlands is the high spatial complexity, comprising a ditch network and relatively small land patches subjected to different management practices such as mowing, grazing, fertilization, and drainage (Minkkinen and Laine 2006; Vermaat and Hellmann 2010). Such different management practices lead to distinct plant communities, ranging from plants adapted to nutrient-poor wet conditions to plants from drier and more productive sites. Inventories of methane emission along this gradient are still scarce and a better spatial resolution is needed to evaluate how different management practices and their combinations affect methane fluxes. The aim of this study was to make a direct link between plant species composition and methane fluxes in an effort to predict methane emissions in a land-use gradient in peatland ecosystems. We used weighted averaging (WA) regression and calibration to derive predicted values of methane flux using plant species composition data.

\section{MeTHODS}

\section{General Approach}

We surveyed methane emissions in two nature reserves (see study sites below). In each of the 
study sites, sampling stations were chosen to cover a range of common land management practices used in Dutch polders, that is, low-lying land that is being reclaimed from a body of water. The survey was designed to comprise a land-use gradient ranging from low management intensity (mowing, with high water levels) to high management intensity (mowing, grazing, and fertilizing, with low water levels), where methane emissions, abiotic conditions, and plant species composition were recorded. We first used canonical correspondence analysis (CCA) to describe the abiotic factors that are related to plant species composition. Then we developed WA models to derive a quantitative inference of methane fluxes from the plant species composition data. WA models were developed first separately for each site and than with the complete data set to provide a more general model.

\section{Study Sites}

Two extensive peatland sites were chosen for study: Nieuwkoopse Plassen (hereafter called Nieuwkoop) is situated in the western part of the Netherlands $\left(52^{\circ} 08^{\prime} \mathrm{N}, 4^{\circ} 48^{\prime} \mathrm{E}\right)$ and Het Guisveld is situated in the polder Westzaan in the north-western part of the Netherlands $\left(52^{\circ} 29^{\prime} \mathrm{N}, 4^{\circ} 47^{\prime} \mathrm{E}\right)$. The reserves comprise narrow grassland and reed fields on peat soil surrounded by ditches. Both sites are subjected to management and it is possible to find small patches of peatland side-by-side subjected to different practices: reed or hay mowing, presence of grazing cattle and addition of manure. In each of the sites, we selected five field stations to represent a land-use gradient regarding the above-mentioned management practices (Table 1). The stations also represent a gradient in mean groundwater level, ranging from 9 to $35 \mathrm{~cm}$ below the soil surface. At the intensive end of the land-use gradient, plant communities are dominated by fast growing grass species: Lolium perenne and Agrostis stolonifera in Nieuwkoop and $L$. perenne and Poa trivialis in Guisveld. At the lower end of the gradient, plant communities are dominated by nutrient-poor moisture tolerant species: Sphagnum palustre and Phragmites australis in Nieuwkoop and S. palustre and S. fallax in Guisveld.

\section{Environmental Variables}

In each of the sampling stations described above, five collars were permanently placed $10-\mathrm{cm}$ deep into the soil for the $\mathrm{CH}_{4}$ flux measurements. Collars were placed at least $5 \mathrm{~m}$ apart. To determine gas fluxes, a vented, transparent acrylic chamber (23$\mathrm{cm}$ diameter and $55-\mathrm{cm}$ height) was placed in the gutter-shaped rim of the collars and the space between the chamber and the collar was sealed with water. Gas samples were taken from the septum located on the top of the chambers by using a twoway needle and evacuated 12-ml septum-capped glass vials (Exetainers, Labco Ltd., High Wycombe, UK). Samples were taken on time zero and every $15 \mathrm{~min}$ for $45 \mathrm{~min}$. Vials were transported to the laboratory and $\mathrm{CH}_{4}$ concentrations were determined on a HP 5890A (Agilent Technologies, Santa Clara, CA, USA) gas chromatograph fitted with a Porapak N column and flame ionization detector.

Table 1. Soil Characteristics (pH, Exchangeable $\mathrm{N}$ and $\mathrm{P}$, Total $\mathrm{P}, \mathrm{C}: \mathrm{N}$ Ratio) and Mean Groundwater Level and Mean $\mathrm{CH}_{4}$ Fluxes for Field Stations in the Land-Use Gradient for the Two Study Sites: Nieuwkoop and Guisveld

\begin{tabular}{|c|c|c|c|c|c|c|c|}
\hline & $\mathrm{pH}$ & $\begin{array}{l}\operatorname{exch~} \mathbf{N} \\
\left(\mu \mathrm{g} \mathrm{g}^{-1} \mathrm{DW}\right)\end{array}$ & $\begin{array}{l}\text { exch P } \\
\left(\mu \mathrm{g} \mathrm{g}^{-1} \mathrm{DW}\right)\end{array}$ & $\begin{array}{l}\text { Total P } \\
\left(\mathrm{mg} \mathrm{g}^{-1} \mathrm{DW}\right)\end{array}$ & $\mathrm{C}: \mathrm{N}$ & $\begin{array}{l}\text { Water } \\
\text { level }(\mathrm{cm})\end{array}$ & $\begin{array}{l}\mathrm{CH}_{4} \\
\left(\mathrm{mg} \mathrm{m}^{-2} \mathrm{~h}^{-1}\right)\end{array}$ \\
\hline \multicolumn{8}{|c|}{ Nieuwkoop } \\
\hline 1MGF & $4.7 \pm 0.1^{\mathrm{a}}$ & $37.1 \pm 6.2^{\mathrm{a}}$ & $55.4 \pm 19.5^{\mathrm{ad}}$ & $2.9 \pm 0.68^{\mathrm{a}}$ & $11 \pm 0.7^{\mathrm{a}}$ & $-35 \pm 17^{\mathrm{a}}$ & $0.03 \pm 0.1^{\mathrm{a}}$ \\
\hline $2 \mathrm{MG}$ & $4.7 \pm 0.1^{\mathrm{a}}$ & $43.6 \pm 7.8^{a}$ & $29.5 \pm 9.5^{\mathrm{ab}}$ & $2.2 \pm 0.24^{\mathrm{ab}}$ & $11 \pm 0.6^{a}$ & $-21 \pm 7^{\mathrm{b}}$ & $1.96 \pm 1.1^{\mathrm{b}}$ \\
\hline $3 M G$ & $5.4 \pm 0.1^{\mathrm{b}}$ & $30.2 \pm 14.8^{\mathrm{a}}$ & $15.3 \pm 6.9^{b c}$ & $1.4 \pm 0.21^{b c}$ & $14 \pm 0.4^{\mathrm{a}}$ & $-16 \pm 11^{b c}$ & $3.25 \pm 2.5^{b c}$ \\
\hline $4 \mathrm{M}$ & $4.7 \pm 0.2^{\mathrm{a}}$ & $25.0 \pm 12.9^{\mathrm{a}}$ & $9.8 \pm 7.7^{\mathrm{c}}$ & $0.7 \pm 0.17^{c}$ & $27 \pm 6.0^{\mathrm{b}}$ & $-12 \pm 5^{c}$ & $5.70 \pm 4.1^{c}$ \\
\hline $5 \mathrm{M}$ & $3.1 \pm 0.1^{\mathrm{c}}$ & $20.2 \pm 18.0^{\mathrm{a}}$ & $112.2 \pm 49.6^{\mathrm{d}}$ & $1.8 \pm 0.2 \mathrm{l}^{\mathrm{d}}$ & $11 \pm 0.3^{c}$ & $-13 \pm 8^{c}$ & $8.68 \pm 14.6^{c}$ \\
\hline \multicolumn{8}{|l|}{ Guisveld } \\
\hline $6 \mathrm{MG}$ & $4.8 \pm 0.4^{\mathrm{ab}}$ & $59.0 \pm 9.8^{\mathrm{ab}}$ & $14.8 \pm 4.7^{\mathrm{a}}$ & $1.4 \pm 0.40^{\mathrm{ab}}$ & $16 \pm 2.7^{\mathrm{ac}}$ & $-29 \pm 14^{a}$ & $1.59 \pm 2.5^{\mathrm{a}}$ \\
\hline $7 \mathrm{MG}$ & $5.2 \pm 0.3^{\mathrm{a}}$ & $76.6 \pm 23.0^{\mathrm{bc}}$ & $68.5 \pm 28.2^{b}$ & $2.0 \pm 0.35^{\mathrm{b}}$ & $13 \pm 0.7^{\mathrm{ab}}$ & $-19 \pm 21^{b}$ & $2.44 \pm 5.7^{\mathrm{a}}$ \\
\hline $8 \mathrm{MG}$ & $5.6 \pm 0.2^{\mathrm{a}}$ & $104.8 \pm 19.8^{\mathrm{c}}$ & $86.0 \pm 32.6^{\mathrm{b}}$ & $0.9 \pm 0.35^{\mathrm{b}}$ & $19 \pm 4.1^{\mathrm{b}}$ & $-16 \pm 15^{b}$ & $1.56 \pm 1.3^{\mathrm{a}}$ \\
\hline $9 \mathrm{M}$ & $4.2 \pm 0.8^{\mathrm{b}}$ & $13.4 \pm 12.4^{\mathrm{d}}$ & $39.0 \pm 24.4^{\mathrm{ab}}$ & $2.2 \pm 0.45^{\mathrm{a}}$ & $12 \pm 0.4^{c}$ & $-19 \pm 5^{b}$ & $5.60 \pm 8.9^{\mathrm{a}}$ \\
\hline $10 M$ & $4.3 \pm 0.4^{\mathrm{b}}$ & $25.1 \pm 29.4^{\mathrm{ad}}$ & $102.3 \pm 81.5^{\mathrm{b}}$ & $1.4 \pm 0.52^{\mathrm{ab}}$ & $17 \pm 1.6^{c}$ & $-9 \pm 3^{c}$ & $32.54 \pm 27.5^{\mathrm{b}}$ \\
\hline
\end{tabular}

Field stations are numbered from one to ten and the letters in the labels denote the local management practices: mowing $(M)$, grazing $(G)$ and fertilizing $(F)$. Means $\pm S D$ are shown $(n=5)$. Different lowercase letters represent significant difference between stations within study sites $(P<0.05$ in Tukey test after one-way ANOVA). 
Helium was used as the carrier gas with $25 \mathrm{ml} \mathrm{min}^{-1}$ flow and $500 \mu \mathrm{l}$ samples were injected. Air temperature was taken into account while converting $\mathrm{CH}_{4}$ concentrations into milligrams by using the ideal gas law equation. The flux was then calculated using linear regressions against time. Methane fluxes were measured five times within 1 year: July, August, September, and October 2008 and April 2009. The period between April and October represents the higher $\mathrm{CH}_{4}$ emission values for Dutch peatlands (Hendriks and others 2007; van den Pol-van Dasselaar and others 1999). Accordingly, all our sampling stations showed emission peaks between July and September (data not shown), indicating that the measurements between April and October included most of the annual emission. An extra measurement during the winter (February 2009) was performed, but it was not included in the analysis because it presented virtually no $\mathrm{CH}_{4}$ emission (data not shown). For the data analysis, the average flux per collar was used.

Simultaneously to the measurements of $\mathrm{CH}_{4}$ flux, soil temperature and water table level were measured at the side of the chamber. Narrow $(5 \mathrm{~cm})$ permanent pits were made at the side of each collar where water level was measured relative to the soil surface. Negative values indicate water levels below soil surface and positive values indicate water levels above soil surface. Soil temperature was measured at $10-\mathrm{cm}$ depth using a soil thermometer at the side of each collar.

Next to each collar, a soil sample (0-10-cm deep) was collected and analyzed for $\mathrm{pH}$ of the soil solution, exchangeable $\mathrm{N}$ and $\mathrm{P}$ and total $\mathrm{N}, \mathrm{P}$, and $\mathrm{C}$. Subsamples of $10 \mathrm{~g}$ fresh soil were dried $\left(70^{\circ} \mathrm{C}\right.$, $48 \mathrm{~h})$ to determine the fresh mass/dry mass ratio for each sample. The $\mathrm{pH}$ was determined in a suspension of $10 \mathrm{~g}$ fresh soil with $25 \mathrm{ml} \mathrm{l} \mathrm{M} \mathrm{KCl}$ after shaking for $2 \mathrm{~h}$. In the same extract, exchangeable nitrate and ammonium were determined on a continuous flow Analyzer (Skalar SA-40, Skalar, Breda, The Netherlands). Exchangeable phosphate was determined by extracting $10 \mathrm{~g}$ of fresh soil in $25 \mathrm{ml}$ ammonium lactate-acetic acid solution. Total $\mathrm{P}$ was determined by digesting $1 \mathrm{~g}$ of soil sample in $37 \% \mathrm{HCl}: 65 \% \mathrm{HNO}_{3}(1: 4, \mathrm{v} / \mathrm{v})$. These diluted digests and extraction solutions were analyzed colorimetrically at $880 \mathrm{~nm}$ after reaction with molybdenum blue. Total $\mathrm{N}$ and $\mathrm{C}$ were determined by dry combustion with an elemental analyzer (Flash EA 1112, Thermo Corporation Italia, Rodana, Italy).

\section{Species Composition}

In each collar, the vegetation was surveyed once in July, when vegetation is reaching the peak of biomass (hereafter referred to vegetation stands). Plants rooted within the collars were identified to species and the percentage cover was recorded as a measurement of abundance. The percentage cover was estimated independently by at least two observers and the average value was recorded. Difference between observers' estimates was usually not higher than 5\%. Species nomenclature follows Van der Meijden (1990).

\section{Statistical Analyses}

Vegetation stands were ordinated by CCA to determine the environmental variables that constrain plant species composition. CCA was performed using the package "vegan" from R2.7.0 software. Models to derive predictions of $\mathrm{CH}_{4}$ flux were developed using WA regression and calibration (Ter Braak and Van Dam 1989). For both CCA and WA, only species with two or more occurrences were included in the analyses and cover was used as a measurement of abundance. WA assumes a unimodal response of species to a certain environmental variable. This means that species will present their maximum abundance at their preferred or optimum position in the environmental gradient. We expected that plant community composition in these peatlands would be determined largely by the same environmental variables that drive $\mathrm{CH}_{4}$ emissions. We are aware that plants do not respond directly to $\mathrm{CH}_{4}$ fluxes nor have optimal $\mathrm{CH}_{4}$ flux in a biological sense. Still, the terms optimum and tolerance have been retained for consistency with the literature on gradient analysis. In our study, the term species optimum refers to the more likely average $\mathrm{CH}_{4}$ flux $\left(\mathrm{mg} \mathrm{m}^{-2} \mathrm{~h}^{-1}\right)$ given the presence of the referred species, whereas tolerance is a measure of dispersal around this value (standard deviation).

The development of a WA regression model is a three-step procedure: WA regression, WA calibration, and deshrinking (Ter Braak and Juggins 1993). In WA regression, the estimate of each $k$ species optimum $\left(\hat{u}_{k}\right)$ was derived as the average of $\mathrm{CH}_{4}$ fluxes $\left(x_{i}\right)$ of the $i$ collars where the species is present, weighted by the species abundance $\left(y_{i k}\right)$ :

$$
\hat{u}_{k}=\sum_{i=1}^{n} y_{i k} x_{i} / \sum_{i=1}^{n} y_{i k}
$$


The species tolerance was approximated as the abundance-weighted standard deviation from the species optimum $\left(t_{k}\right)$ :

$$
t_{k}=\sqrt{\sum_{i=1}^{n} y_{i k}\left(x_{i}-\hat{u}_{k}\right)^{2} / \sum_{i=1}^{n} y_{i k}}
$$

In WA calibration an initial prediction $\left(x_{\text {ini }}\right)$ of $\mathrm{CH}_{4}$ fluxes for each collar was calculated. In a simple WA calibration, the $x_{\text {ini }}$ for a given collar was determined as the abundance-weighted average of the optima of the present species. WA calibration downweighting species' tolerances were also performed (optional tolerance downweighting in brackets):

$$
x_{\text {ini }}=\sum_{k=1}^{m} y_{i k} \hat{u}_{k}\left(1 / t_{k}^{2}\right) / \sum_{k=1}^{m} y_{i k}\left(1 / t_{k}^{2}\right)
$$

A deshrinking procedure was performed for correcting the inherent bias toward the median of the observed range, which resulted from taking averages twice during WA reconstitution: once in WA regression and once in WA calibration. To derive deshrinking parameters (regression coefficient $b$ and constant $a)$, the initial prediction values $\left(x_{\text {ini }}\right)$ were regressed on the observed values $\left(x_{i}\right)$, socalled classical deshrinking:

$$
x_{\mathrm{ini}}=a+b x_{i}
$$

The final prediction $\left(x_{\mathrm{fin}}\right)$ of $\mathrm{CH}_{4}$ fluxes for each collar was then calculated as:

$$
x_{\mathrm{fin}}=\left(x_{\mathrm{ini}}-a\right) / b
$$

The inverse deshrinking, where $x_{i}$ is regressed on $x_{\text {ini, }}$ minimizes the root mean squared error (RMSE) and was also performed (Ter Braak and Van Dam 1989). The average $\mathrm{CH}_{4}$ fluxes were $\log$ transformed prior to analyses because they were skewed.

Correlation between predicted and observed values and the RMSE were used as criteria of model success and model comparisons. Not only 'apparent' statistics by fitting the model prediction to the training set were calculated, but also the leave-oneout method was used to perform a cross-validation (Ter Braak and Juggins 1993). For a certain WA model, the WA reconstitution was performed more than once, each time leaving out one of the vegetation stands in a turn. The transfer function based on the selected vegetation stands is applied to the omitted one, giving for this stand a prediction and an error prediction (RMSEP). Each stand in turn had then taken the place of a test set, each time of size one. This procedure is particularly recommended for small data sets where randomly splitting the data on training and test sets can lead to a poor estimation of errors. The development and validation of the WA model were performed using the Software C2 version 1.5.1 (Juggins 2007).

WA models were constructed separately for Nieuwkoop and Guisveld. Besides the cross-validation procedure described above, we also used vegetation stands from one site as a test set for the model developed for the other site. The latter was calculated in two ways: (1) using the complete description of species composition and (2) using only the identity of the two dominant species. This was done to evaluate if the identification of only the dominant species is enough to provide good predictions of $\mathrm{CH}_{4}$ emission for a given site. Finally, a WA model with the complete data set (vegetation stands from both Nieuwkoop and Guisveld) was performed to obtain a more general model. This final model was validated against published $\mathrm{CH}_{4}$ emission surveys which also report the composition of the dominant plant species.

\section{RESUltS}

At both sites, the land-use gradient was related to groundwater level (Table 1), showing lower groundwater levels in more intensively used areas. This gradient was followed by $\mathrm{CH}_{4}$ emissions, which showed lower values on intensively used areas with low water levels. Additionally, field stations where grazing cattle were present tended to show higher levels of exchangeable $\mathrm{N}$, mainly in Guisveld (Table 1).

For the Nieuwkoop data set, the first and second axes accounted for $35 \%$ of the total variance of species data. The species-environment correlations for the two first axes were high (0.97 and 0.95, respectively), suggesting a strong relation between vegetation and the environmental variables presented in Figure 1. A Monte Carlo permutation test showed that only the first two axes were statistically significant $(P=0.005$ and $P=0.010$, respectively). Water level, $\mathrm{CH}_{4}$ emission, exchangeable $\mathrm{P}$, and $\mathrm{C}: \mathrm{N}$ ratio were positively correlated with axis $\mathrm{I}$ (intra-set correlations 0.641, 0.659, 0.494, and 0.833 , respectively). Water level also showed a positive correlation with axis 2 (intra-set correlation 0.675). Total $\mathrm{P}$ and $\mathrm{pH}$ showed a strong negative correlation with axis 1 (intra-set correlations -0.865 and -0.857 , respectively).

For the Guisveld data set, the first and second axes accounted for $34 \%$ of the total variance of species data. The species-environment correlations 

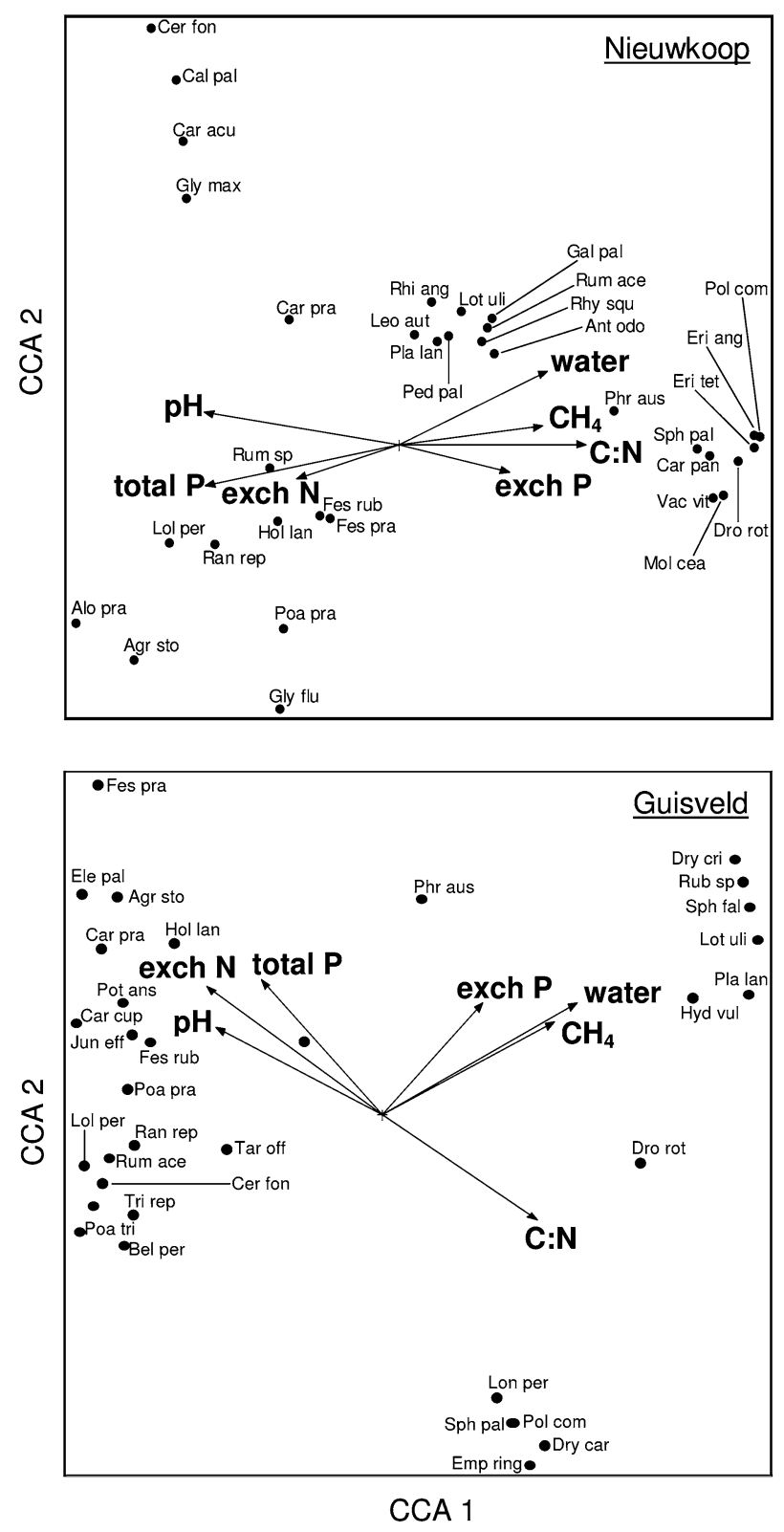

Figure 1. CCA biplots of Nieuwkoop and Guisveld plant species composition in relation to $\mathrm{CH}_{4}$ flux, mean water level, soil $\mathrm{pH}$, exchangeable $\mathrm{N}$ and $\mathrm{P}$, total $\mathrm{P}$ and $\mathrm{C}: \mathrm{N}$ ratio. Species codes are as in Appendix 1 in Supplementary material.

for the two first axes were high (0.99 and 0.95, respectively), suggesting a strong relation between vegetation and the environmental variables (Figure 1). A Monte Carlo permutation test also showed that only the first two axes were statistically significant $(P=0.005$ and $P=0.013$, respectively). $\mathrm{CH}_{4}$ emission, water level, and $\mathrm{C}: \mathrm{N}$ ratio were positively correlated with axis 1 (intra-set correlations $0.638,0.724$, and 0.577 , respectively).
Exchangeable $\mathrm{N}$, total $\mathrm{P}$, and $\mathrm{pH}$ were negatively correlated with axis 1 (intra-set correlations $-0.650,-0.448$, and -0.615 , respectively). Axis 2 was a combination of exchangeable $\mathrm{N}$ and $\mathrm{P}$ and total P (intra-set correlations 0.542, 0.476, and 0.573 , respectively).

WA models allowed reliable reconstruction of $\mathrm{CH}_{4}$ fluxes in individual sites (Table 2). We used the lower value of RMSEP as a criterion to choose the best model, because it represents the best estimate of error derived from the cross-validation procedure. For the Nieuwkoop data set, the best model was obtained with downweighting tolerances and inverse deshrinking (Table 2, Figure 2). For the Guisveld data set, the best model was obtained with classical calibration and inverse deshrinking (Table 2, Figure 2). The use of one site as a test set for the model developed for the other site (that is, calculating predicted values for one site based on the species optima derived from the other site) also yielded good predictions (Figure 3). The limited species similarity restricted the number of vegetation stands that could be used for this validation test. We only used vegetation stands for which species in common between Nieuwkoop and Guisveld comprised at least $70 \%$ of plant cover. The error estimations from these validations were similar to those from the models for the individual sites (Figure 3). Using only the two dominant species for the same vegetation stands provided virtually the same predictive power as compared to the full-species list (Figure 3). In most of the cases predicted values were almost identical.

The WA model for the complete data set (Nieuwkoop and Guisveld combined) also yielded good predictive power. Species optima ranged from 0.07 to $38.81 \mathrm{CH}_{4} \mathrm{mg} \mathrm{m}^{-2} \mathrm{~h}^{-1}$ (Appendix 1 in Supplementary material, Figure 4). Although tolerances also varied widely among species, downweighting tolerances did not affect the model performance (Table 2). The best models were obtained with inverse deshrinking (Table 2, Figure 5).

We found three published studies reporting both $\mathrm{CH}_{4}$ fluxes and the identity of the dominant species (Table 3) the same as in our survey. The study by Hendriks and others (2007) was the only one reporting species abundance; for the other studies we considered an even distribution between the reported dominant species. Van den Pol-van Dasselar and others (1999) reported $\mathrm{CH}_{4}$ emission from three sites within the study area but described plants species composition in general for the study area as a whole. Therefore, we used the average $\mathrm{CH}_{4}$ flux for the three sites as the observed value. 
Table 2. Validation of Predictions of $\mathrm{CH}_{4}$ Emission from Plant Species Composition for Nieuwkoop, Guisveld, and the Complete Data Set

\begin{tabular}{|c|c|c|c|c|c|}
\hline \multirow[t]{2}{*}{ Calibration } & \multirow[t]{2}{*}{ Deshrinking } & \multirow[t]{2}{*}{ RMSE } & \multirow[t]{2}{*}{$r$} & \multicolumn{2}{|c|}{ Leave-one-out } \\
\hline & & & & RMSEP & $r_{\text {jack }}$ \\
\hline \multicolumn{6}{|l|}{ Nieuwkoop } \\
\hline WA & Inverse & 0.16 & 0.83 & 0.20 & 0.74 \\
\hline WA & Classical & 0.19 & 0.83 & 0.23 & 0.76 \\
\hline WATOL & Inverse & 0.13 & 0.90 & $0.17^{*}$ & 0.81 \\
\hline WATOL & Classical & 0.14 & 0.90 & 0.19 & 0.82 \\
\hline \multicolumn{6}{|l|}{ Guisveld } \\
\hline WA & Inverse & 0.23 & 0.88 & $0.32^{*}$ & 0.75 \\
\hline WA & Classical & 0.26 & 0.88 & 0.36 & 0.76 \\
\hline WATOL & Inverse & 0.19 & 0.92 & 0.36 & 0.67 \\
\hline WATOL & Classical & 0.21 & 0.92 & 0.39 & 0.68 \\
\hline \multicolumn{6}{|c|}{ Complete data set } \\
\hline WA & Inverse & 0.20 & 0.85 & $0.26^{*}$ & 0.76 \\
\hline WA & Classical & 0.24 & 0.85 & 0.30 & 0.77 \\
\hline WATOL & Inverse & 0.18 & 0.89 & 0.26 & 0.75 \\
\hline WATOL & Classical & 0.20 & 0.89 & 0.29 & 0.76 \\
\hline
\end{tabular}

Apparent RMSE (in $\log 1+\mathrm{CH}_{4} m g m^{-2} h^{-1}$ ) and Pearson correlation coefficient $(r)$ between predicted values and the training set and $\mathrm{RMSEP}$ in log $1+\mathrm{CH}_{4} \mathrm{mg}^{-2} \mathrm{~h}^{-1}$ )

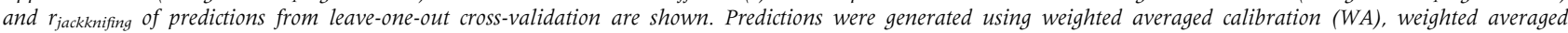
calibration with tolerances downweighted (WATOL), and both classical and inverse deshrinking procedures. Models with lower RMSEP are marked with asterisk.

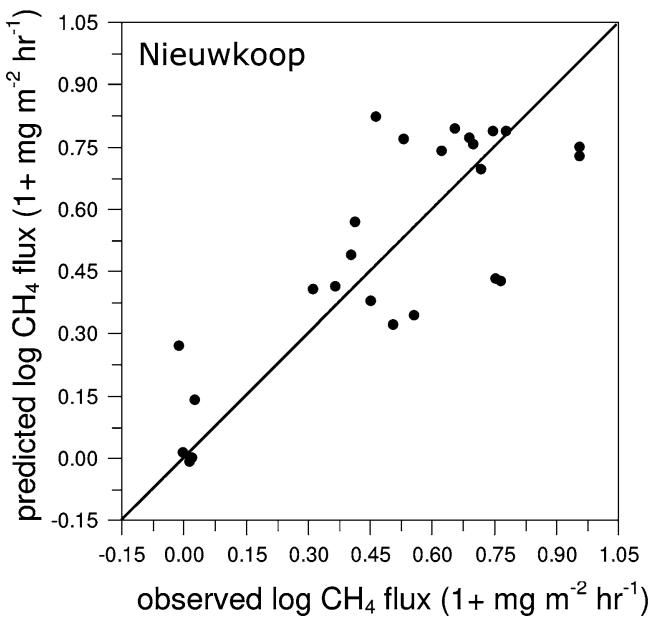

The predictions based on the species optima from our final model showed good agreement with the published $\mathrm{CH}_{4}$ fluxes (Table 3).

Mean water level was the abiotic factor that was most strongly correlated with $\mathrm{CH}_{4}$ (Figure 1). The relation between these two variables was better described by an inverse relationship (Figure 6). The use of mean water level to infer $\mathrm{CH}_{4}$ flux yielded the same predictive power $(\mathrm{RMSE}=0.26 \log 1+$ $\mathrm{CH}_{4} \mathrm{mg} \mathrm{m}^{-2} \mathrm{~h}^{-1}$ ) as the WA model with plant species composition for the complete data set $\left(\right.$ RMSEP $\left.=0.26 \log \mathrm{l}+\mathrm{CH}_{4} \mathrm{mg} \mathrm{m}^{-2} \mathrm{~h}^{-1}\right)$.

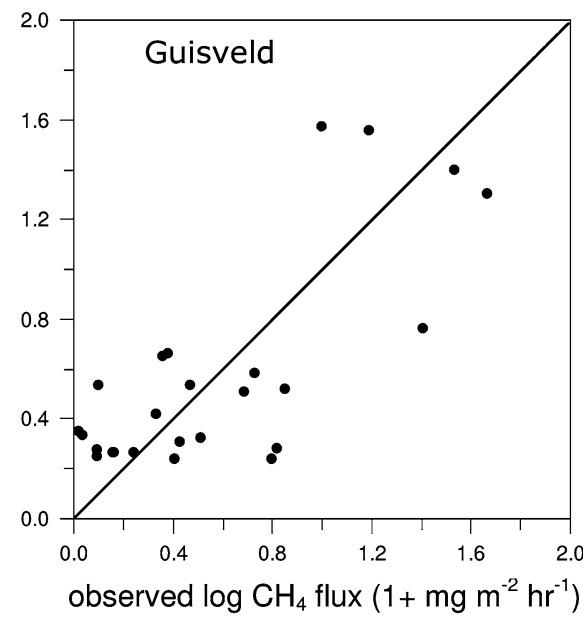

Figure 2. Plots of observed versus WA-predicted $\mathrm{CH}_{4}$ flux values for Nieuwkoop and Guisveld. The 1:1 line is shown. See Table 2 for RMSEP and $r_{\text {jackknifing }}$ values.

\section{Discussion}

\section{Linking $\mathrm{CH}_{4}$ Emission with Abiotic Variables and Plant Species Composition}

An important rationale behind our approach is that there should be a link among abiotic variables, methane emissions, and plant species composition. We found that land-use change, from wetlands to drier agricultural lands, affected the environmental variables that are related to both $\mathrm{CH}_{4}$ flux and plant species composition. The pattern in environmental variables was very similar in the two study sites, as 

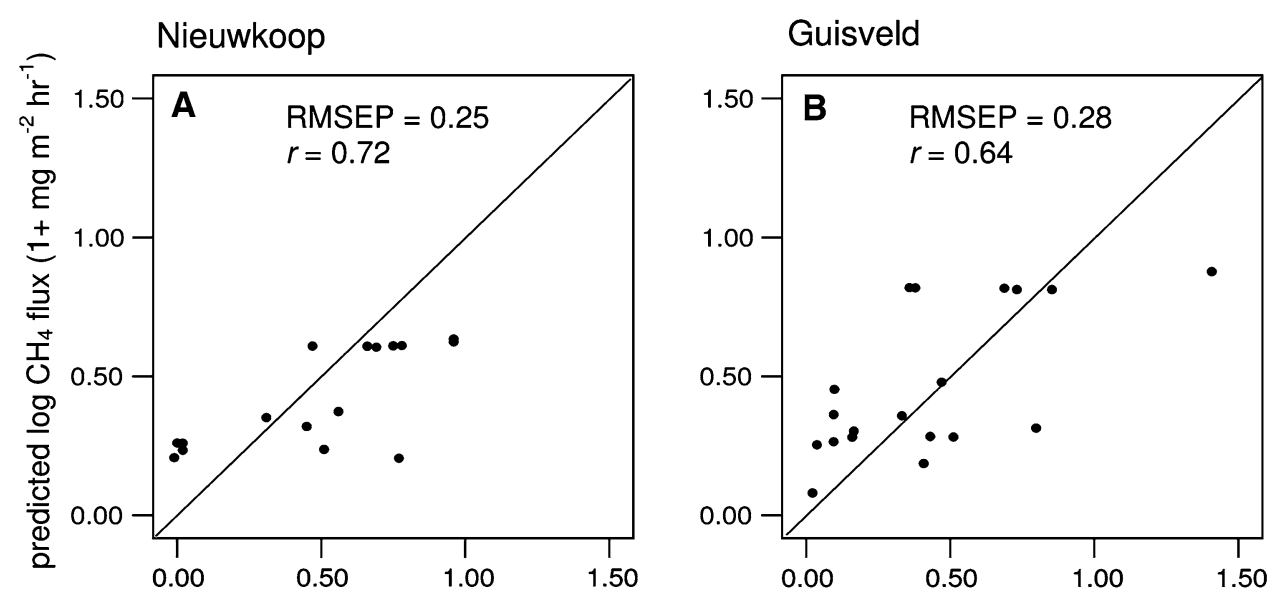

Figure 3. Plots of observed versus predicted $\mathrm{CH}_{4}$ flux values for the test sets. Nieuwkoop predictions were calculated using optima derived from Guisveld data set and vice versa. A, B Predictions were calculated with the complete description of species composition. Only vegetation stands for which species in common between Nieuwkoop and Guisveld comprise at least $70 \%$ of plant cover were included in the analysis.

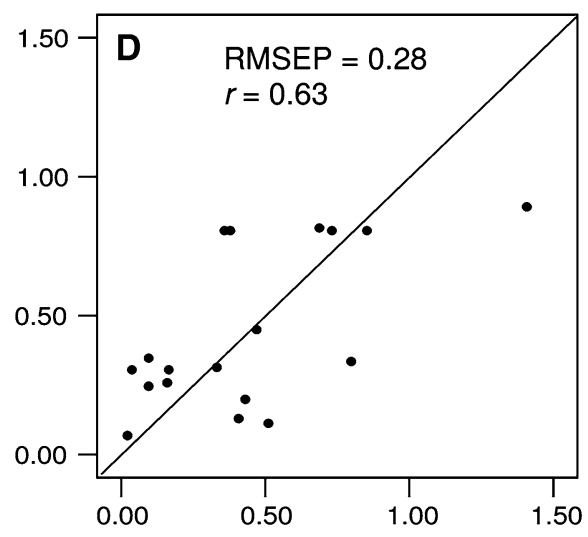
C, D The same vegetation stands were used but only the dominant species were used for deriving predictions. The $1: 1$ line is shown.

observed $\log \mathrm{CH}_{4}$ flux $\left(1+\mathrm{mg} \mathrm{m}^{-2} \mathrm{hr}^{-1}\right)$

the main gradient in both sites was related to water level. It is well known that water level can strongly affect biogeochemical features of peatlands (Limpens and others 2008; Wilson and others 2008). Mean water table level was positively correlated to $\mathrm{CH}_{4}$ flux, exchangeable $\mathrm{P}$, and $\mathrm{C}: \mathrm{N}$ ratios, whereas negatively related to $\mathrm{pH}$, exchangeable $\mathrm{N}$, and total P. It has been shown that drainage of peatlands stimulates decomposition and nutrient mineralization of organic matter, leading to an increase in $\mathrm{N}$ availability (Grootjans and others 1986; Lamers and others 2002). In contrast, $P$ availability decreases because the capacity of the sediment to bind $\mathrm{P}$ increases during desiccation due to the oxidation of Fe. Thus, the opposing effect of water level on the availability of both $\mathrm{N}$ and $\mathrm{P}$ in addition to the direct effect of the degree of water logging probably drives major changes in vegetation composition. Moreover, sites with lower water tables are often subjected to grazing and/or fertilization imposing further changes in vegetation toward fast growing and grazing-tolerant species, such as grasses. Thus, water level regulation is a severe environmental modification caused by land-use change in peat- lands. Our results suggest that the effects of water level on both $\mathrm{CH}_{4}$ fluxes and plant species composition make the latter a useful proxy of the former.

\section{Predicting $\mathrm{CH}_{4}$ Emission From Plant Species Composition}

The aim of this study was to make a direct link between plant species composition and $\mathrm{CH}_{4}$ fluxes in an effort to predict $\mathrm{CH}_{4}$ emissions in a land-use gradient in peatland ecosystems. Indeed, we found that the WA models provided good predictions of $\mathrm{CH}_{4}$ flux for both individual sites and the complete data set. Using one site as a test set for the model developed for the other site also yielded good predictions. This indicates that the use of optima estimated in one given site can provide robust estimations for other sites. Moreover, using only the dominant species provided very similar results as compared to the complete community composition. The Guisveld site showed higher fluxes as compared to Nieuwkoop and that was observed mainly in the extremes of the emission gradient. 


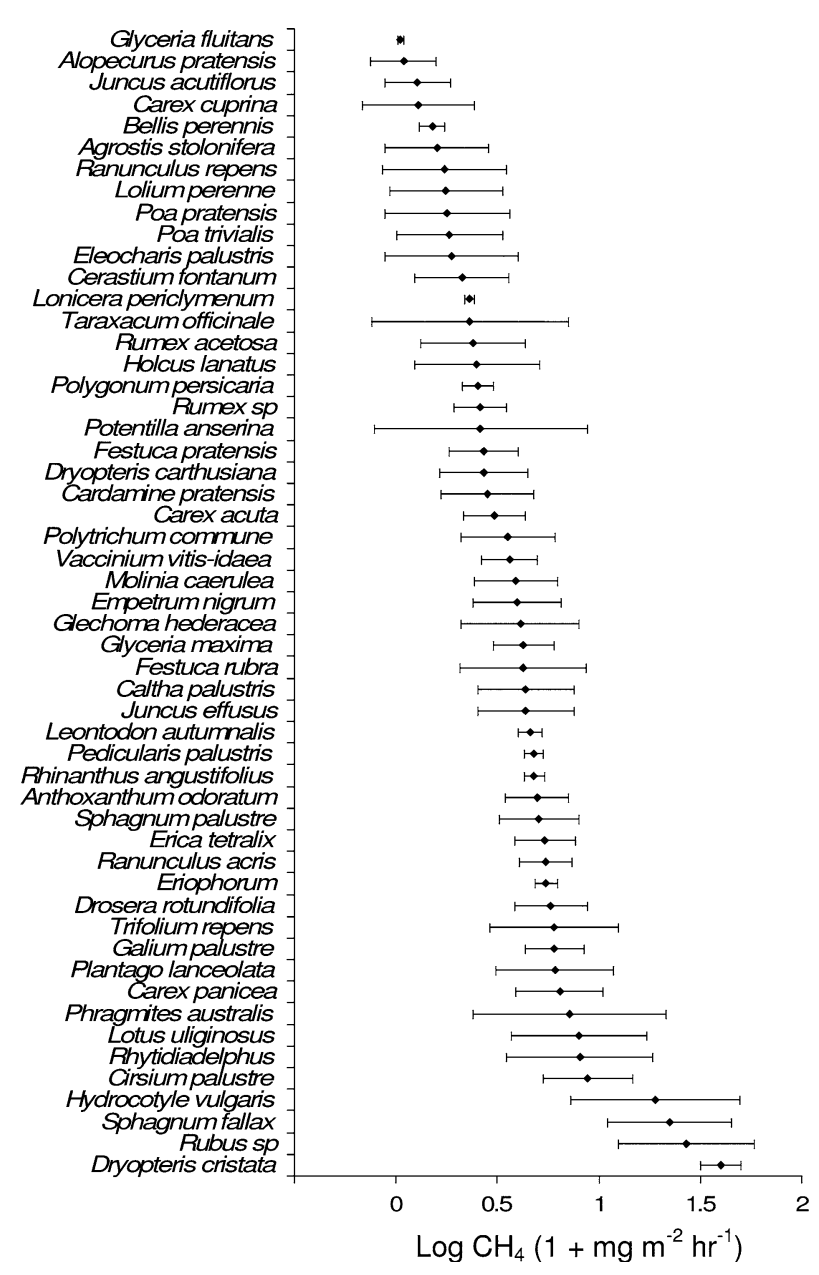

Figure 4. Methane flux weighted averaged optima and tolerances of plant species derived from the complete data set.

Consequently, species present on the lower (for example, A. stolonifera and Alopecurus pratensis) and the higher (for example, Lotus uliginosus) ends of the emission gradient showed a considerably higher optimum in the Guisveld site. This probably occurred because the Guisveld site presented considerably higher availability of exchangeable $\mathrm{N}$ and higher $\mathrm{pH}$ values as compared to Nieuwkoop, which have been shown to significantly affect $\mathrm{CH}_{4}$ emission in peatlands (Aerts and Toet 1997; Le Mer and Roger 2001). However, these differences between sites in some species' optima were not strong enough to produce poor predictions of $\mathrm{CH}_{4}$ emissions. Additionally, the model with the complete data set performed as well as the models for individual sites. This shows that the construction of models including species occurrences on a broader set of environmental conditions can provide good

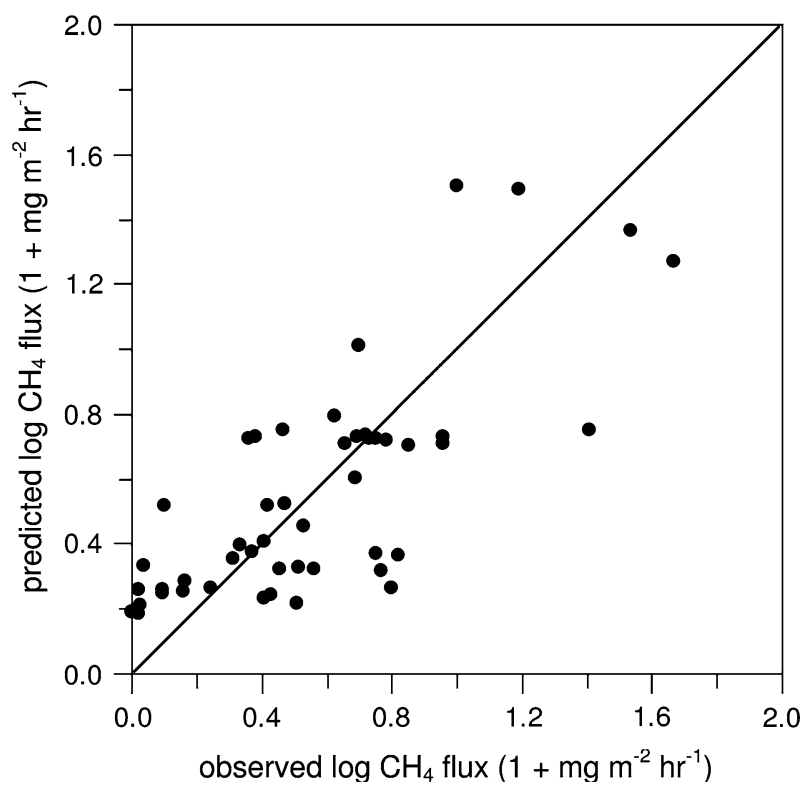

Figure 5. Plot of observed versus WA-predicted $\mathrm{CH}_{4}$ flux values for the complete data set. The $1: 1$ line is shown. RMSEP $=0.26\left(\log \mathrm{l}+\mathrm{CH}_{4} \mathrm{mg} \mathrm{m}^{-2} \mathrm{~h}^{-1}\right)$ and $r_{\text {jackknifing }}=0.76$.

estimates of species optima that are applicable to a broad spatial scale.

An important issue is whether our results can be validated against other data sets. Our model with the complete data set provided good predictions for the three published works describing both $\mathrm{CH}_{4}$ fluxes and plant species composition in common with our survey (see Table 3, Hendriks and others 2007; Schrier-Uijl and others 2009; van den Polvan Dasselaar and others 1999). This further confirms that the identity of the dominant species is enough to provide good predictions of $\mathrm{CH}_{4}$ fluxes as none of these works provided detailed descriptions of the plant species composition. Therefore, quick characterizations of the dominant plant species can be used to generate $\mathrm{CH}_{4}$ predictions. This is particularly important for the application of our approach on large peatlands ecosystems (for example, peatlands in Canada, Greenland, Siberia), where detailed characterization of the plant community on large spatial scales might not be feasible.

In further support of our approach it should be noted that the good performance of our model $\left(r_{\text {jackknifing }}=0.76\right)$ was comparable to that of mechanistic models developed for natural wetland ecosystems: Granberg and others (1997) reported relationships between observed and predicted values with $r$ ranging from 0.70 to 0.87 , whereas Zhang and others (2002) reported relationships with $r$ ranging from 0.61 to 0.87 . However, 
Table 3. Validation of WA-Model with the Complete Data Set Using Published $\mathrm{CH}_{4}$ Flux Surveys

\begin{tabular}{|c|c|c|c|}
\hline Reference & $\begin{array}{l}\text { Observed } \\
\mathrm{CH}_{4} \text { flux }\end{array}$ & $\begin{array}{l}\text { Predicted } \\
\mathrm{CH}_{4} \text { flux }\end{array}$ & Dominant species \\
\hline Hendriks and others (2007) & 5.25 & 4.26 & $\begin{array}{l}\text { P. australis }(34 \%), H \text {. lanatus }(15 \%) \text {, } \\
\text { A. stolonifera }(14 \%) \text {, and J. effusus }(5 \%)\end{array}$ \\
\hline $\begin{array}{l}\text { Van den Pol-van Dasselaar } \\
\text { and others (1999) }\end{array}$ & 3.97 & 4.85 & A. odoratum, $P$. australis, and $M$. caerulea \\
\hline \multicolumn{4}{|l|}{ Schrier-Uijl and others (2009) } \\
\hline Intensively managed & 0.75 & 0.86 & L. perenne and $P$. trivialis \\
\hline Extensively managed & 0.85 & 0.86 & \\
\hline
\end{tabular}

Observed average $\mathrm{CH}_{4}$ fluxes $\left(\mathrm{mg} \mathrm{m} \mathrm{m}^{-2} \mathrm{~h}^{-1}\right)$ and predicted average $\mathrm{CH}_{4}$ flux based on the dominant plant species composition. Species optima used to derive predictions are shown in Appendix 1 in Supplementary material. When estimates of species cover were not given, an even distribution between species per site was assumed. Only the best predictions are shown (WA with inverse deshrinking; $R M S E=0.77 \mathrm{mg} \mathrm{CH} \mathrm{m}^{-2} \mathrm{~h}^{-1}, r_{\text {pearson }}=0.94$ ).

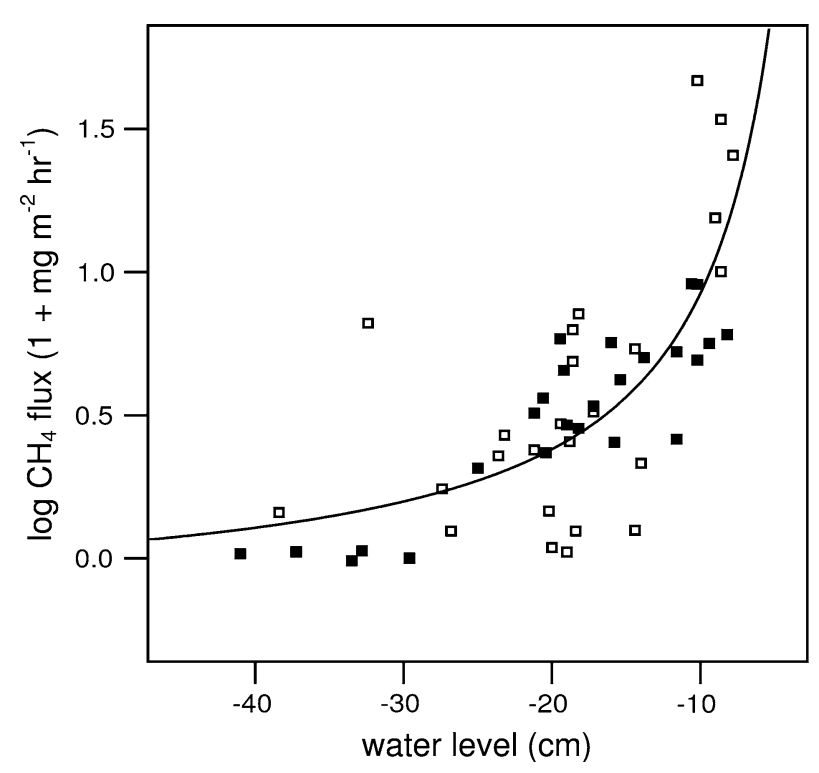

Figure 6. Relationship between mean water level and mean $\mathrm{CH}_{4}$ emission. Each point represents a collar in Nieuwkoop (filled symbols) and Guisveld (open symbols). $\log \mathrm{CH}_{4}=(-10.99 /$ water level $)-0.15 ; F=138 ; P<$ $0.001 ; \operatorname{RMSE}=0.26\left(\log \mathrm{l}+\mathrm{CH}_{4} \mathrm{mg} \mathrm{m}^{-2} \mathrm{~h}^{-1}\right) ; R^{2}=$ 0.57 .

mechanistic models often need complex input parameters, such as potential $\mathrm{CH}_{4}$ production, potential $\mathrm{CH}_{4}$ oxidation, plant $\mathrm{CH}_{4}$ transport coefficients, net primary productivity, decomposition rates, soil organic matter content, soil temperature, and soil bulk density (Granberg and others 1997; Van Huissteden and others 2006; Zhang and others 2002). Many of these parameters are often not available or are difficult to measure and their variation between sites or due to management regimes is still poorly understood. We propose the use of plant species composition as a simple and effective alternative for deriving predictions of $\mathrm{CH}_{4}$ emissions, although mechanistic models might provide important insights on the relative importance of different drivers and processes involved in $\mathrm{CH}_{4}$ emission.

In this study we focused mainly on vascular plants species composition as indicator of methane emission as mosses are largely absent from managed peatlands. For natural peatland ecosystems, mosses might be better indicators. Bubier and others (1995) used WA regression and calibration to predict $\mathrm{CH}_{4}$ emissions form bryophyte species composition in boreal peatlands. The correlation between their predicted values and the training set ( $r=0.84-0.89)$ showed comparable fit as that of our best model with the complete data set $(r=0.89)$. However, they did not perform crossvalidation, such as the leave-one-out procedure, making it difficult to compare reliable error estimates.

In our study, both mean water level and plant species composition were good predictors of $\mathrm{CH}_{4}$ emission, showing the same predictive power. This further confirms that plant species composition strongly responds to water level variation. However, water level showed high variability through time, a feature that is often reported for peatland ecosystems (Bubier and others 1995; van den Polvan Dasselaar and others 1999). The average standard deviation in water level for a collar was $10.4 \mathrm{~cm}$, representing about $25 \%$ of the range of the recorded mean water levels $(-41$ to $-7 \mathrm{~cm})$. Measuring water level once could lead to an invalid estimation of the mean water level on a chamber location, leading to erroneous estimates of $\mathrm{CH}_{4}$ emission. Importantly, the error on estimating $\mathrm{CH}_{4}$ flux from the mean water level is likely to be higher on sites with higher water levels, and consequently higher $\mathrm{CH}_{4}$ emissions, due to the shape of the 
inverse relationship between these two variables (Figure 6). An error in mean water level estimation from -15 to $-10 \mathrm{~cm}$ would imply an overestimation of $5.07 \mathrm{mg} \mathrm{CH}_{4} \mathrm{~m}^{-2} \mathrm{~h}^{-1}$, whereas an error in mean water level estimation from -35 to $30 \mathrm{~cm}$ would lead to an overestimation of only $0.19 \mathrm{mg}$ $\mathrm{CH}_{4} \mathrm{~m}^{-2} \mathrm{~h}^{-1}$ (compare equation from Figure 6). In contrast, plant species composition is much more stable in time because it reflects integrated environmental factors over a longer period of time; sampling only once a year can provide a good estimate of plant community composition. Therefore, plant species composition can be seen as a stable and robust proxy for average $\mathrm{CH}_{4}$ emission. Vegetation surveys are often available for managed peatlands and are nowadays available as digital maps. This makes it possible to estimate methane fluxes over large spatial scales.

Two points merit further attention. First, at present the domain of application of this model is restricted to peatlands. Some of the species listed in Figure 4 can occur in different ecosystems, but the optimal $\mathrm{CH}_{4}$ flux estimates for such species are representative only for peatland ecosystems. Moreover, the utilization of the optima reported here for peatlands in other regions (for example, Eastern Europe, North America) needs further validation. Applying this approach in a greater diversity of wetland types and regions would provide species optima that are possibly applicable to different regions of the globe or show in which cases species optima should be derived specifically for a given region. Second, the model assumes that there is equilibrium between plant species composition and environmental conditions. However, there may be a time-lag between environmental change and plant species response (Bartholomeus and others 2008), temporarily decoupling plant community composition and $\mathrm{CH}_{4}$ flux. The extent of this time-lag deserves further attention, but there is evidence that herbaceous species can respond rapidly to environmental changes in peatlands. For instance, Komulainen and others (1999) showed that re-establishment of higher water tables in formerly drained peatlands in Finland resulted in rapid change of plant species composition. Eriophorum vaginatum increased in cover from virtually zero to values around $60 \%$ only one growing season after rewetting and to $80 \%$ after the second growing season. Thus, the use of plant species composition is likely to provide good estimates of $\mathrm{CH}_{4}$ emission after environmental changes on a relative short time scale, being a useful tool for monitoring future changes in $\mathrm{CH}_{4}$ emission due to land-use or climate changes.

\section{Effect of Land-Use Change on GHG Balance}

Peatlands provide unique conditions for long-term $\mathrm{C}$ sequestration into the soil in the form of organic matter. However, this $\mathrm{C}$ storage process is intimately linked to $\mathrm{CH}_{4}$ emission which can counteract this. Therefore, to evaluate the role of wetlands in global warming it is necessary to calculate the GHG balance, considering the $\mathrm{CH}_{4}$ global warming potential under different time horizons (Whiting and Chanton 2001). This is an important issue, as peatlands that have a zero net $\mathrm{C}$ balance, can still be contributing to the greenhouse effect. This is because the $\mathrm{C}$ uptake is always originating from assimilated $\mathrm{CO}_{2}$, whereas $\mathrm{C}$ can be released both in the form of $\mathrm{CO}_{2}$ and $\mathrm{CH}_{4}$. As the warming potential of $\mathrm{CH}_{4}$ is more than 20 times as high as that of $\mathrm{CO}_{2}$, it is of the utmost importance to know how much of the emitted $\mathrm{C}$ is released as $\mathrm{CH}_{4}$. Land-use change can strongly affect this balance through water level regulation. The return of agricultural peatlands into wet, semi-natural ecosystems, has been suggested as a measure to increase C sequestration (Aerts 2000), but the underlying increase in $\mathrm{CH}_{4}$ emission and the consequences for the GHG balance remains poorly documented. Studies comparing $\mathrm{CH}_{4}$ emissions under different land-use scenarios often compare data from distant areas (Langeveld and others 1997; Van den Bos 2003). The land-use gradient studied here presented a wide range of methane emissions. The lower emission values were found in areas with higher land-use intensity (from $0.03 \pm 0.1$ to $1.59 \pm 2.5 \mathrm{mg} \mathrm{CH}_{4} \mathrm{~m}^{-2} \mathrm{~h}^{-1}$ ) and are comparable with values reported for dryer grasslands on peat (Van den Pol-van Dasselaar and others 1997). The higher emission values were found in areas with lower land-use intensity (from $8.68 \pm 14.6$ to $32.54 \pm 27.5 \mathrm{mg} \mathrm{CH}_{4} \mathrm{~m}^{-2} \mathrm{~h}^{-1}$ ). These values are at the higher limit of the range found for wetlands, being comparable with those of pristine peatland ecosystems (Bartlett and Harriss 1993). Our results corroborate that $\mathrm{CH}_{4}$ emission can increase strongly with rewetting even in a small spatial scale. This increase was particularly strong where water levels were kept higher than $10 \mathrm{~cm}$ below surface.

\section{ConClusions}

This study shows that plant species composition is a good proxy for $\mathrm{CH}_{4}$ emissions in peatland ecosystems after land-use changes. WA regression and 
calibration proved to be a simple but powerful analytical tool to derive predictions of $\mathrm{CH}_{4}$ emissions from plant species composition data. Plant species composition has the advantage of being more stable through time compared to groundwater level (that is, the best abiotic descriptor of $\mathrm{CH}_{4}$ emission). Moreover, we showed that a quick characterization of vegetation composition by the dominant species only provides equally good predictions of $\mathrm{CH}_{4}$ emissions. Further application of this approach in different wetland types would provide species optima that are applicable in a broader spatial scale than presented here.

Countries committed to the Kyoto Protocol need to report annual GHG inventories. Reporting requirements increased with the adoption of Good practice guidance for land use, land-use change, and forestry (Penman and others 2003). Yet estimation of methane emissions due to land-use needs to be improved to match such requirements (Lapveteläinen and others 2007). The combination of the approach presented here with plant species inventories can be used to improve GHG inventories in countries where peatlands comprise a considerable portion of the landscape. Furthermore, using plant species to estimate $\mathrm{CH}_{4}$ emissions from peatlands will help to determine the land-use scenario that provides higher $\mathrm{C}$ accumulation with lower $\mathrm{CH}_{4}$ emission.

\section{ACKNOWLEDGEMENTS}

We would like to thank Peter van Bodegom and Bob Douma for stimulating discussions, Ellen Dorrenpaal for the identification of Sphagnum species, Fritz Hellmann for fieldwork assistance, and Rob Broekman for assistance with soil analyses. Monica Turner, Gaius Shaver, and two anonymous referees provided valuable comments on an earlier draft of this manuscript. We also thank the Natuurmonumenten and the Staatsbosbeheer for allowing the use of their land and facilities. This study was funded by the Dutch National Research Programme Climate Changes and Spatial Planning (BSIK-KvR ME5).

\section{OPEN ACCESS}

This article is distributed under the terms of the Creative Commons Attribution Noncommercial License which permits any noncommercial use, distribution, and reproduction in any medium, provided the original author(s) and source are credited.

\section{REFERENCES}

Aerts R. 2000. Possibilities for carbon storage in grasslands on peat in the Netherlands. In: van Amstel A, Ed. Monitoring $\mathrm{CO}_{2}$ sinks in the Netherlands: priorities for improvement. Wageningen: Wageningen University. p 25-7.

Aerts R, De Caluwe H. 1999. Nitrogen deposition effects on carbon dioxide and methane emissions from temperate peatland soils. Oikos 84:44-54.

Aerts R, Ludwig F. 1997. Water-table changes and nutritional status affect trace gas emissions from laboratory columns of peatland soils. Soil Biol Biochem 29:1691-8.

Aerts R, Toet S. 1997. Nutritional controls on carbon dioxide and methane emission from Carex-dominated peat soils. Soil Biol Biochem 29:1683-90.

Bartholomeus RP, Witte JPM, van Bodegom PM, Aerts R. 2008. The need of data harmonization to derive robust empirical relationships between soil conditions and vegetation. J Veg Sci 19:799-808.

Bartlett KB, Harriss RC. 1993. Review and assessment of methane emissions from wetlands. Chemosphere 26:261-320.

Bubier JL. 1995. The relationship of vegetation to methane emission and hydrochemical gradients in northern peatlands. J Ecol 83:403-20.

Bubier JL, Moore TR, Juggins S. 1995. Predicting methane emission from bryophyte distribution in northern Canadian peatlands. Ecology 76:677-93.

Glatzel S, Forbrich I, Kruger C, Lemke S, Gerold G. 2008. Small scale controls of greenhouse gas release under elevated $\mathrm{N}$ deposition rates in a restoring peat bog in NW Germany. Biogeosciences 5:925-35.

Gorham E. 1991. Northern peatlands: role in the carbon-cycle and probable responses to climatic warming. Ecol Appl 1: 182-95.

Granberg G, Mikkela C, Sundh I, Svensson BH, Nilsson M. 1997. Sources of spatial variation in methane emission from mires in northern Sweden: a mechanistic approach in statistical modeling. Global Biogeochem Cycles 11:135-50.

Grootjans AP, Schipper PC, Vanderwindt HJ. 1986. Influence of drainage on $\mathrm{N}$-mineralization and vegetation response in wet meadows. 2. Cirsio-Molinietum stands. Acta OecologicaOecologia Plantarum 7:3-14.

Hendriks DMD, Van Huissteden J, Dolman AJ, Van der Molen MK. 2007. The full greenhouse gas balance of an abandoned peat meadow. Biogeosciences 4:411-24.

Juggins S. 2007. C2 Version 1.5 user guide. Software for ecological and palaeoecological data analysis and visualisation. Newcastle upon Tyne: Newcastle University.

Komulainen VM, Tuittila ES, Vasander H, Laine J. 1999. Restoration of drained peatlands in southern Finland: initial effects on vegetation change and $\mathrm{CO}_{2}$ balance. J Appl Ecol 36:634-48.

Lamers LPM, Smolders AJP, Roelofs JGM. 2002. The restoration of fens in the Netherlands. Hydrobiologia 478:107-30.

Langeveld CA, Segers R, Dirks BOM, Van den Pol-van Dasselaar A, Velthof GL, Hensen A. 1997. Emissions of $\mathrm{CO}_{2}, \mathrm{CH}_{4}$ and $\mathrm{N}_{2} \mathrm{O}$ from pasture on drained peat soils in the Netherlands. Eur J Agron 7:35-42.

Lapveteläinen T, Regina K, Perala P. 2007. Peat-based emissions in Finland's national greenhouse gas inventory. Boreal Environ Res 12:225-36. 
Le Mer J, Roger P. 2001. Production, oxidation, emission and consumption of methane by soils: a review. Eur J Soil Biol 37:25-50.

Limpens J, Berendse F, Blodau C, Canadell JG, Freeman C, Holden J, Roulet N, Rydin H, Schaepman-Strub G. 2008. Peatlands and the carbon cycle: from local processes to global implications-a synthesis. Biogeosciences 5:1475-91.

Minkkinen K, Laine J. 2006. Vegetation heterogeneity and ditches create spatial variability in methane fluxes from peatlands drained for forestry. Plant Soil 285:289-304.

Penman J, Gytarsky M, Hiraishi T, Krug T, Kruger D, Pipatti R, Buendia L, Miwa K, Ngara T, Tanabe K, Wagner F. 2003. Good practice guidance for land use, land-use change and forestry. Hayama: Institute for Global Environmental Strategies (IGES) for the IPCC.

Schrier-Uijl AP, Kroon PS, Leffelaar PA, Van Huissteden JC, Berendse F, Veenendaal EM. 2010. Methane emissions in two drained peat agro-ecosystems with high and low agricultural intensity. Plant Soil 329:509-20.

Ter Braak CJF, Juggins S. 1993. Weighted averaging partial least-squares regression (Wa-Pls) -an improved method for reconstructing environmental variables from species assemblages. Hydrobiologia 269:485-502.

Ter Braak CJF, Van Dam H. 1989. Inferring pH from diatoms: a comparison of old and new calibration methods. HydrobioIogia 178:209-23.

Van den Bos R. 2003. Restoration of former wetlands in the Netherlands; effect on the balance between $\mathrm{CO}_{2}$ sink and $\mathrm{CH}_{4}$ source. Neth J Geosci Geologie En Mijnbouw 82:325-31.

Van den Pol-van Dasselaar A, Van Beusichem ML, Oenema O. 1997. Effects of grassland management on the emission of methane from intensively managed grasslands on peat soil. Plant Soil 189:1-9. van den Pol-van Dasselaar A, van Beusichem ML, Oenema O. 1999. Methane emissions from wet grasslands on peat soil in a nature preserve. Biogeochemistry 44:205-20.

Van der Meijden R. 1990. Heukels' flora van Nederland. Groningen: Wolters-Noordhoff bv.

Van Huissteden J, Van den Bos R, Alvarez IM. 2006. Modelling the effect of water-table management on $\mathrm{CO}_{2}$ and $\mathrm{CH}_{4}$ fluxes from peat soils. Neth J Geosci-Geologie En Mijnbouw 85:318.

Veenendaal EM, Kolle O, Leffelaar PA, Schrier-Uijl AP, Van Huissteden J, Van Walsem J, Moeller F, Berendse F. 2007. $\mathrm{CO}_{2}$ exchange and carbon balance in two grassland sites on eutrophic drained peat soils. Biogeosciences 4:1027-40.

Vermaat JE, Hellmann F. 2010. Covariance in water- and nutrient budgets of Dutch peat polders: what governs nutrien retention? Biogeochemistry. doi:10.1007/s10533-009-9395-8.

Waddington JM, Roulet NT, Swanson RV. 1996. Water table control of $\mathrm{CH}_{4}$ emission enhancement by vascular plants in boreal peatlands. J Geophys Res-Atm 101:22775-85.

Whalen SC. 2005. Biogeochemistry of methane exchange between natural wetlands and the atmosphere. Environ Eng Sci 22:73-94.

Whiting GJ, Chanton JP. 2001. Greenhouse carbon balance of wetlands: methane emission versus carbon sequestration. Tellus Ser B Chem Phys Meteorol 53:521-8.

Wilson D, Alm J, Laine J, Byrne KA, Farrell EP, Tuittila ES 2008. Rewetting of cutaway peatlands: are we re-creating hot spots of methane emissions? Restor Ecol. doi:10.1111/j.1526100X.2008.00416.X.

Zhang Y, Li CS, Trettin CC, Li H, Sun G. 2002. An integrated model of soil, hydrology, and vegetation for carbon dynamics in wetland ecosystems. Global Biogeochem Cycles 16:1-17. 